\title{
EMPREENDEDORISMO RURAL TEM ENDEREÇO?
}

Alexandre Godinho Bertoncello, Aline de Morais Cristo de Melo

Universidade do Oeste Paulista - UNOESTE, Curso Administração, Agronegócio, Ciências Contábeis e MBA em Agronegócio. E-mail: bertoncello@unoeste.br

\section{RESUMO}

É notória a necessidade do espirito empreendedor em todas as atividades econômicas, no campo temos incertezas ainda maiores que na área urbana e por isso temos um imperativo maior se impondo com mais ênfase. $O$ empreendedorismo é um assunto estudado cada vez mais em faculdades, artigos e entidades diversas com intuito de analisar e aprimorar o perfil e características do empreendedor de negócios, para obter o sucesso em uma produção rural. Esse trabalho buscou identificar semelhanças e diferenças do empreendedor rural de pequeno porte e do ambiente que o cerca, foi utilizado como método a comparação entre empreendedores rurais da cidade de Narandiba interior de São Paulo e do distrito de Nova Porto XV na cidade de Bataguassu no estado de Mato Grosso do Sul. Concluiu-se que apesar de ambientes externos diferentes os agricultores que obtiveram êxito nas suas atividades econômicas tinham características pessoais e a estrutura de negócio muito parecidas. Persistência, um olhar atento as mudanças de mercado, e participavam de algum tipo de associação ou cooperativa.

Palavras-chave: Agricultura familiar, Agronegócio, Estratégia, Agricultura.

\section{DOES RURAL ENTREPRENEURSHIP HAVE ADDRESS?}

\begin{abstract}
It is evident the need of entrepreneurial spirit in all economic activities, in the countryside we have even greater uncertainties than those from the urban area and, therefore, we have a greater imperative that is imposed with more emphasis. Entrepreneurship is a subject increasingly studied in colleges, articles and several entities in order to analyse and improve the profile and characteristics of business entrepreneur to obtain success in a rural production. This study sought to identify similarities and differences of small-sized rural entrepreneur and the environment that surrounds him. It was used as a method, the comparison between rural entrepreneurs from the city of Narandiba in the countryside of São Paulo and the district of Nova Porto XV in the city of Bataguassu in the state of Mato Grosso do Sul. It was concluded that despite differences in external environments, farmers who have been successful in their economic activities had personal characteristics and business structure that were very similar, such as persistence, a watchful eye to market changes, and were participating in some kind of association or cooperative.
\end{abstract}

Keywords: Family farming, Agribusiness, Strategy, Agriculture.

\section{INTRODUÇÃO}

O primeiro grande empreendimento da humanidade foi a revolução agrícola que possibilitou a criação das cidades e o fim do sistema nômade. Podemos afirmar assim, que o empreendedor rural sempre existiu, mas atualmente o ambiente é outro, as novas tecnologias da revolução verde, os problemas econômicos e as questões ambientais exigem do agricultor uma postura empresarial, porém, pouco se fala em plano de negócios e estratégia de mercado para o produtor da área rural.

No Brasil, a Empresa Brasileira de Pesquisa Agropecuária (EMBRAPA), é a grande fomentadora do campo, graças a estudos e pesquisas que auxiliam o produtor rural a aumentar sua produtividade com custos acessíveis, com criatividade e, sem degradar o meio ambiente tendo em vista que adotam os pressupostos da responsabilidade social. Segundo 
as informações fornecidas por meio do site da empresa:

A Embrapa foi criada em 26 de abril de 1973 e é vinculada ao Ministério da Agricultura, Pecuária e Abastecimento (Mapa). Desde a nossa criação, assumimos um desafio: desenvolver, em conjunto com nossos parceiros do Sistema Nacional de Pesquisa Agropecuária (SNPA), um modelo de agricultura e pecuária tropical genuinamente brasileiro, superando as barreiras que limitavam a produção de alimentos, fibras e energia no nosso País. (EMBRAPA, 2016, grifo nosso)

Como é sabido, é importante para o produtor rural ter uma visão ampla do mercado, o que é possível graças ao uso de ferramentas diversas, entre as quais destacamos: a própria experiência do produtor rural, o qual constrói conhecimento; a informação gerada por pesquisas acadêmicas e, ainda, consultorias que são disponibilizadas por entes públicos ou privados.

A mescla dos itens supracitados, quando bem utilizados possibilitará ao agricultor usar os recursos disponíveis de forma eficiente e assim será possível planejar, administrar e lucrar com a atividade agrícola independentemente do tamanho da propriedade rural. Para Girotto e Talamini:

$\mathrm{Na}$ decisão do produtor agrícola, no curto, no médio ou no longo prazo, o conhecimento de técnicas de administração rural desempenha papel preponderante em função das constantes mudanças que podem ocorrer no setor, tais como disponibilidades de recursos e tecnologias, preços de insumos e produtos, políticas agrícolas, representando riscos e incertezas.

(GIROTTO;

TALAMINI, 1998, p. 296)

Nosso objeto de pesquisa foi analisar a influência que o ambiente externo tem sobre a agricultura familiar e, verificar a capacidade empreendedora dos agricultores independentemente da principal atividade econômica da propriedade. A hipótese é de que a postura empreendedora seja o fator determinante do sucesso, autonomamente do ambiente externo.

\section{METODOLOGIA}

A metodologia teve como fundamento pesquisas bibliográficas, estudadas a fim de compreender como iniciar um empreendimento, planejar, tomar decisões e ainda, apreender quais são as melhores maneiras de administrar uma produção.

Através dos parâmetros encontrados na pesquisa bibliográfica, que determinou qual é o comportamento empresarial necessário para gerenciar uma propriedade rural, nossa pesquisa analisou o perfil de empreendedores rurais em duas regiões diferentes. Observou-se a cadeia de produção de suínos no interior do Estado de Mato Grosso do Sul, analisando desde a chegada dos animais até o envio destes para o abate. Em concomitância, foi examinado o processo de produção de frutas dos agricultores no município de Narandiba, no interior do Estado de São Paulo.

Essa abordagem tem como escopo verificar o comportamento do empresário rural, em particular daqueles oriundos da agricultura familiar, considerando-se que os agentes econômicos que apresentaram perfil e atitudes descritas como ideais pela literatura, tiveram os investimentos analisados com o objetivo de verificar como políticas macroeconômicas influenciaram o comportamento dos investimentos das duas microrregiões.

A análise macroeconômica teve dois momentos, sendo o primeiro baseado em dados nacionais que certamente influenciam de forma mais ou menos igual todos os investidores. 0 segundo foi a observação de uma política monetária com impacto regional: o projeto MICROBACIAS II do Estado de São Paulo e do Banco Mundial. Ressalta-se que essa última análise possibilita fazer um comparativo de comportamento empresarial observando empresas parecidas com cenários macroeconômicos diferentes. 


\section{RESULTADOS E DISCUSSÃO}

No primeiro resultado encontrado, ficou claro que o empreendedor de sucesso tem um perfil parecido, independentemente do tamanho da empresa, da localização ou da área de atuação. Oliveira (2014) ressalta que todas as organizações lideradas por empreendedores possuem de maneira implícita ou explicita a visão, missão e valores da mesma. Assim como ocorre em relação aos propósitos e objetivos econômicos, as estratégias de políticas macro e as políticas de crescimento da empresa, também só existem quando temos empreendedores.

Ainda de acordo com Oliveira (2014), a empresa que tem empreendedores normalmente tem projetos e planos de ações para aumentar a competitividade e atingir as metas. Desta forma é possível inferir que o sucesso empresarial nasce do empreendedor, o qual representa todas as características presentes nos trabalhos acadêmicos e, que reforçam a eficiência e eficácia empresarial.

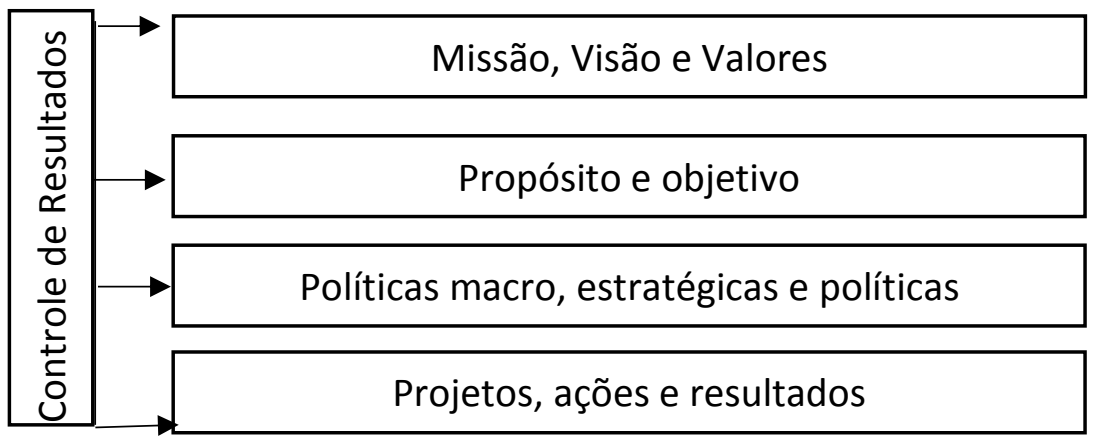

Figura 1. Empresa com empreendedores

Fonte: Oliveira (2014), p. 267, adaptado pelos autores

Apesar da similaridade do perfil, é importante compreender a cadeia produtiva de cada uma das realidades analisadas. Na criação suína do distrito de Nova Porto XV, o produtor, ao iniciar sua criação de suínos, deve estar atento às condições do animal e, às reações possíveis caso os cuidados sejam rejeitados, tendo em vista que é no mesmo local de criação que será feito o abate. Neste sentido, de acordo com Sobestiansky, Barcellos e Sesti (1998):

A introdução de animais num meio ambiente contendo uma flora microbiana substancialmente diferente daquela em que foram criados gera três tipos e riscos:

- Introdução de novas doenças no plantel;

- Desequilíbrio da flora microbiana da criação, precipitando o aparecimento de doenças que se encontram latentes nesse ambiente; ou

- Infecção do (s) animal (is) introduzidos com agentes
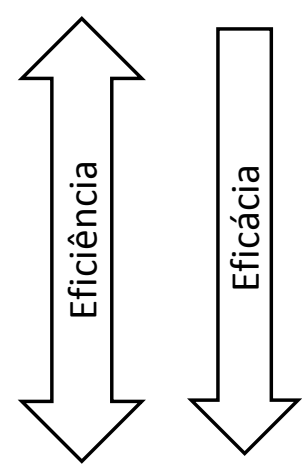

patogênicos presentes no sistema de produção que o (s) comprou. (SOBESTIANSKY; BARCELLOS; SESTI, 1998, p. 337)

O estado de saúde do animal é um dos fatores que o produtor precisa ter mais cuidado, tendo em vista que pode acarretar em sérias consequências, tais como a falta de crescimento do animal ou a morte, riscos que levam ao prejuízo na produção. Para evitar tais prejuízos e transtornos na criação, Sobestiansky, Barcellos e Sesti (1998) ressaltam cinco tipos de cuidados que devem ser levados em consideração quando pensamos em um Sistema de Produção de Suínos:

- $\quad$ Status de saúde do rebanho de origem dos animais; origem

- $\quad$ Exame dos animais no SPS de

- $\quad$ Certificado de garantia;

- Realização de quarentena nos animais a serem introduzidos; e

- Realização da aclimatação dos animais introduzidos.

Em outras palavras, devem ser analisadas: a procedência do animal, as 
certificações, os nutrientes, as vitaminas necessárias, o ambiente e o clima, entre outros critérios. Todo o conjunto deve ser levado em consideração e analisado com minúcia, a fim de que o resultado seja um animal saudável e pronto para ser comercializado.

Após todos os cuidados em relação ao animal, outro aspecto importante a ser considerado é a logística, pois, o embarque e transporte dos suínos, se for mal feito, pode resultar em prejuízos tanto para o comprador quanto para a empresa frigorífica, sendo que os danos incluem desde a diminuição de peso, até a morte.

O responsável pelo transporte deve verificar se o suíno está saudável, se houve algum tipo de alimentação antes do transporte, qual a condição e funcionamento da rampa, o montante de espaço disponível, entre outros. Além disso, quando o veículo utilizado para o transporte de animais ao frigorífico possui uma área útil suficiente para garantir uma boa ventilação e, permitir que o animal possa deitar, é possível que os prejuízos ocasionados pelo transporte, diminuam consideravelmente. (SOBESTIANSKY; WENTZ; SILVEIRA; SESTI, 1998).

Ressalta-se ainda que esses cuidados, além de evitar prejuízos, também servem para evitar riscos, tais como fraturas e uma sobrecarga de stress desnecessário. Neste sentido, dada a importância e relevância destas ações para aprimorar as condições de tratamento dos animais e o retorno financeiro dos produtores rurais, se houver dificuldades em situações como essas, deve-se buscar apoio em associações rurais da região. Para Veiga:

Trata-se de encorajar os municípios rurais a se associarem com o objetivo de valorizar o território que compartilham, fornecendo às associações os meios necessários ao desencadeamento do processo. Ou seja, o papel dos governos federal e estaduais deve ser o de estimular iniciativas que no futuro poderão ser autofinanciadas, mas que dificilmente surgirão, ou demorarão muito para surgir, se não houver o indispensável empurrão inicial. (VEIGA, 2001, p. 111)

Neste sentido, o empreendedor rural precisa buscar informações sobre todo o processo produtivo a fim de obter melhorias na sua produção, sendo que a melhor forma disponível de acesso a estas informações para os pequenos agricultores é por meio de associações, governos e bancos. Os Bancos, por financiarem investimentos para pequenos agricultores, disponibilizam informações de mercado, pois têm interesse no sucesso dos empreendimentos.

Além disso, independentemente da atividade agrícola, os investimentos são sempre um aspecto importante a ser considerado e, por mais difícil que seja, as decisões precisam ser tomadas, sendo necessário, para tanto, analisar a complexidade, os riscos e as oportunidades.

Em relação ao segundo caso, a complexidade do agricultor que produz proteína animal é maior do que a dos fruticultores. Por exemplo, na cadeia produtiva de Narandiba a produção de frutas da região é tradicional, os produtores dominam as técnicas produtivas e, tem a segurança de parcerias como a do CEAGESP-SP e, das compras governamentais tais como: Programa Nacional de Alimentação Escolar - PNAE; Programa de Aquisição de Alimentos PAA - CONAB e, o Programa de Alimentos para os Presídios, em parceria com o Governo do Estado e com a Secretaria da Administração Penitenciária - SAP.

O ambiente favorável encontrado pelos produtores do interior de São Paulo é otimizado pelos incentivos estaduais, sendo que o programa MICROBACIAS I e II, por exemplo, deram aos produtores rurais de SP uma possibilidade de investimento que não foi observada no MS.

No entanto, como analisado por Santos e Bertoncello (2015), não basta ter ambientes favoráveis no âmbito estatual e federal, pois a morosidade de agentes municipais, e particularmente, a fragilidade da gestão empresarial por parte dos agricultores, pode diminuir a possibilidade de melhoria da eficiência, inibindo a eficácia do empresário agrícola.

Se ambientes favoráveis não significam melhorias nos níveis de eficácia e eficiência, mas as questões externas desfavoráveis seguramente afetam as atividades econômicas dentro e fora do campo, o Brasil está vivendo a maior crise econômica dos últimos anos. 
Por esse motivo o empreendedor precisa estar atento à conceitos simples de gerenciamento e de resultado. $\mathrm{O}$ gráfico a seguir demonstra as variações do PIB apontadas pelo IBGE e confirmadas pelo Banco Central Brasileiro desde 1961, chegando às previsões do Fundo Monetário Internacional (doravante FMI) para 2016 e 2017.

No gráfico é possível observar que nunca houve dois anos seguidos de diminuição do PIB na história brasileira, como ocorreu em 2015 e 2016, além da ausência de picos de crescimento nos anos anteriores e posteriores às crises, como aconteceu em 1981, 1983, 1990, 1992 e 2009.

Em outras palavras, quando é somado o acumulo do crescimento do PIB entre os anos de 2011 até a previsão de 2017, o resultado é um número negativo na ordem de $-0,56 \%$, o que leva à conclusão de que a capacidade de gerar riqueza por meio de bens e serviços no ano de 2017 será menor do que o potencial que o Brasil tinha em 2011.

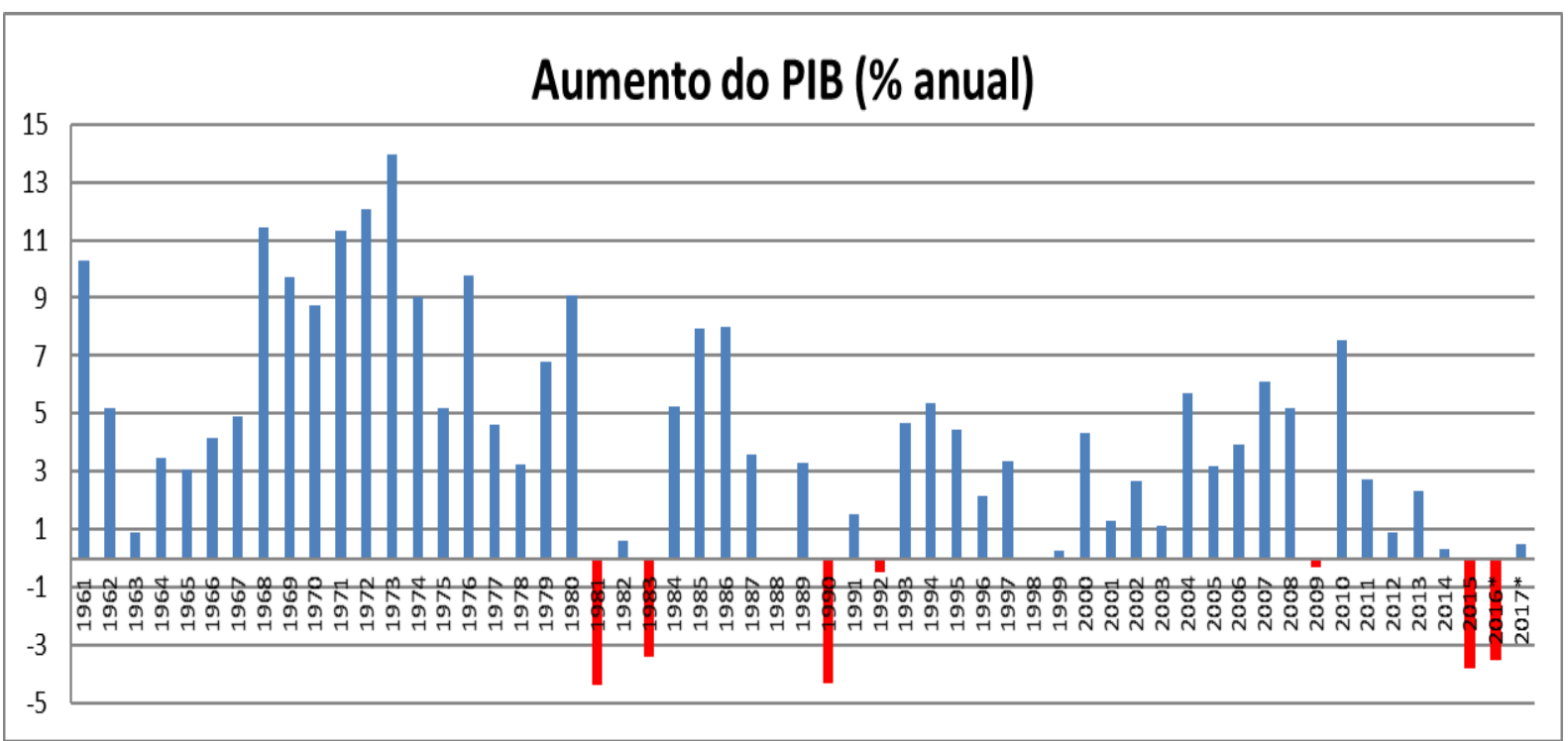

Gráfico 1. Aumento do PIB

Fonte: Banco Central e as previsões de 2016* e 2017* FMI

Após a análise dos diversos cenários, fica claro que as diferentes atividades no campo exigem diferentes habilidades, trazendo desafios igualmente diversos. As barreiras de entrada e, de permanência no mercado de suínos na cidade de Bataguassu traz, por exemplo, desafios maiores do que àqueles vivenciados nas fruticulturas em Narandiba.

Destaca-se ainda que, o mercado no estado de São Paulo é mais maduro, resultando em atividades agrícolas com maior estabilidade e programas estaduais como o MICROBACIAS, que possibilita melhores oportunidades para a agricultura familiar. Por outro lado, essas facilidades têm baixo impacto quando se considera que dentro das propriedades existe um agricultor tradicional e não um empreendedor rural.

Finalmente, o momento histórico que estamos vivenciando pode influenciar nos resultados de maneira negativa, tanto na economia e no comportamento, quanto na sensibilidade ao risco. Assim, um comportamento muito conservador encontrado, pode se modificar em pesquisas futuras, quando o ambiente macroeconômico for modificado.

\section{CONCLUSÃO}

O empreendedorismo rural é um assunto com muito conteúdo a ser estudado, razão pela qual, certamente, demanda estudos futuros e novas pesquisas. No entanto, com a realização deste trabalho foi possível averiguar algumas das capacidade e características do empreendedor, entre as quais podemos citar: a criação e visualização de oportunidades, a autoconfiança e a liderança.

Contudo, o estudo também possibilitou a constatação de que o sucesso do empreendedor é alcançado por meio de um plano de negócios bem estruturado. Assim, todo empreendedor deve pesquisar, planejar e analisar o plano que será implantado na empresa. No caso do produtor rural, este deve ser pensado e 
implantado em correlação com as características da empresa rural.

Por mais que apareçam riscos e dificuldades, o empreendedorismo pode transformar o potencial latente em casos práticos, principalmente se forem observados, em seu plano de negócios, os pontos fortes e fracos, as oportunidades e ameaças, e, se forem feitas as análises: financeira, da concorrência e dos clientes.

Todos os agricultores pesquisados trabalhavam de forma cooperada ou associada dentro da cadeia produtiva em que estavam inseridos, sendo que foi verificado um comportamento mais dinâmico e arrojado nos empreendedores de suinocultura na cidade de Bataguassu, apesar destes possuírem condições mais desfavoráveis, quando comparadas às de Narandiba.

\section{REFERÊNCIAS}

Banco Central do Brasil, http://www.bcb.gov.br/pec/Indeco/Port/indeco. asp dados coletados 10 setembro . 2016.

EMBRAPA. Ministério da Agricultura, Pecuária e Abastecimento. Quem somos. Disponível em: https://www.embrapa.br/quem-somos. Acesso em 01 fev. 2016

Fundo Monetário Internacional https://www.imf.org/external/country/bra/index htm?type $=9998$ dados coletados em 15 de setembro 2016.

GIROTTO, A.F. ; TALAMINI, D. J. D. Administração da propriedade suinícola. In: SOBESTIANSKY, J. (Ed.). Suinocultura intensiva: produção manejo e saúde do rebanho. Concórdia: EMBRAPA-CNPSA, 1998. p.292-298.

OLIVEIRA, D. de P. R.; Planejamento estratégico: conceitos, métodos e práticas. 32.ed. São Paulo: Atlas, 2014.

RURAL NEWS. Como iniciar a sua atividade agropecuária. Disponível em < http://www.ruralnews.com.br/visualiza.php?id=8 05 >. Acesso em: 01 fev. 2016

SANTOS, A. H. S. ; BERTONCELLO A. G. Microbacias II: erros e acertos da gestão pública e privada: estudo de caso FAOP. Revista Colloquium Humanarum, v. 12 , n. 4, 2015. DOI 10.5747/CH.2015.V12.N4.

https://doi.org/10.5747/ch.2015.v12.n4

SOBESTIANSKY, J. ; BARCELLOS, D. E. S. N. ; SESTI, L. A. C. Suinocultura Intensiva: produção, manejo e saúde do rebanho. Brasília: EMBRAPA, 1998.
VEIGA, J. E.; O Brasil rural ainda não encontrou seu eixo de desenvolvimento. [S.I.]: [s.n.], 2001.

Recebido para publicação em 26/08/2016

Revisado em 29/09/2016

Aceito em 04/09/2016 